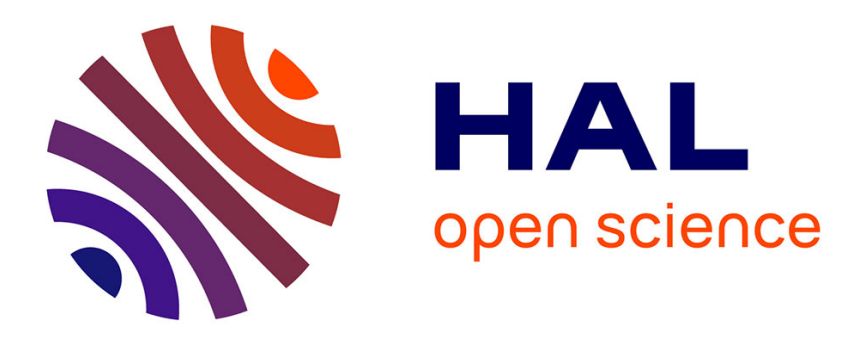

\title{
Absorptive Capacity, Knowledge Spillovers and Incentive Contracts
}

Luis Aguiar, Philippe Gagnepain

\section{To cite this version:}

Luis Aguiar, Philippe Gagnepain. Absorptive Capacity, Knowledge Spillovers and Incentive Contracts. 2021. halshs-03110851

\section{HAL Id: halshs-03110851 https://shs.hal.science/halshs-03110851}

Preprint submitted on 14 Jan 2021

HAL is a multi-disciplinary open access archive for the deposit and dissemination of scientific research documents, whether they are published or not. The documents may come from teaching and research institutions in France or abroad, or from public or private research centers.
L'archive ouverte pluridisciplinaire HAL, est destinée au dépôt et à la diffusion de documents scientifiques de niveau recherche, publiés ou non, émanant des établissements d'enseignement et de recherche français ou étrangers, des laboratoires publics ou privés. 


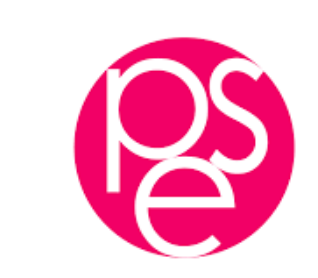

PARIS SCHOOL OFECONOMICS
ECOLE D'ECONOMIE DE PARIS

WORKING PAPER N²021- 05

Absorptive Capacity, Knowledge Spillovers and Incentive Contracts

Luis Aguiar

Philippe Gagnepain

JEL Codes: L25, L51, L92

Keywords: Knowledge spillovers, Absorptive capacity, Cost incentives, effort, Diversity of knowledge, Public transport.

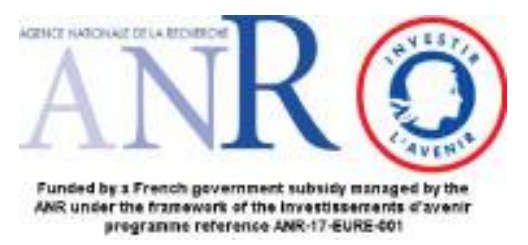




\title{
Absorptive Capacity, Knowledge Spillovers and Incentive Contracts ${ }^{1}$
}

\author{
Luis Aguiar ${ }^{2} \quad$ Philippe Gagnepain ${ }^{3}$
}

July 6, 2020

\begin{abstract}
We attempt to identify and measure potential knowledge spillovers in the French urban transport sector, which is strongly regulated and where a few large corporations are in charge of operating several urban networks simultaneously. We build and estimate a structural cost model where the service is regulated by a local government and is provided by a single operator. Knowledge spillovers are directly linked to the know-how of a specific corporation, but they also depend on the incentive power of the regulatory contract which shapes the effort of the local managers. Exerting an effort in a specific network allows a cost reduction in this network, but it also benefit other networks that are members of the same corporation. Our model provides us with estimates of the operators' absorptive capacity, which is their in-house knowledge power in order to optimally benefit from spillovers. We find that diversity of knowledge across operators of a same corporation improves absorptive capacity and increases the flow of spillovers. Simulation exercises provide evidence of significant reductions in total operating cost following the enlargement of industrial groups.
\end{abstract}

JEL codes: L25, L51, L92

Keywords: Knowledge spillovers, absorptive capacity, cost incentives, effort, diversity of knowledge, public transport

Declarations of interest: none

\footnotetext{
${ }^{1}$ The authors thank the Agence Nationale pour la Recherche (ANR), Ministerio de Educación y Ciencia (SEJ2007-66268) and Ministerio de Economía y Competitividad (ECO2010-20504) for financial assistance. They are grateful to David Martimort, Matilde Machado, Georges Siotis, Bruno Cassiman, Ángel Luis López, as well as seminar participants at the Universitat Autònoma de Barcelona, the CEPR annual IO conference, the annual meeting of the ITEA, the Brazilian Conference Series on Public Procurement and Concession Design, and the International Conference on Contracts, Procurement, and Public-Private Arrangements for very helpful comments. This research was initiated when both authors were affiliated with the Universidad Carlos III de Madrid. All errors are ours.

${ }^{2}$ University of Zurich; Department of Business Administration, Plattenstrasse 14, Zürich, Switzerland; luis.aguiar@business.uzh.ch

${ }^{3}$ Corresponding author. Paris School of Economics-Université Paris 1; 48 bd Jourdan, Paris, France; philippe.gagnepain@univ-paris1.fr
} 


\section{Introduction}

Knowledge spillovers are usually seen as a process in which firms obtain new knowledge in their innovation activity from external sources. They are interpreted as externalities in a competition game where the agents are unable to fully appropriate all benefits from their own R\&D activities. Knowledge spillovers are key ingredients of firms' productivity and economic growth (Jaffe, 1986, Romer, 1990, Grossman and Helpman, 1991). The economic literature has discussed to a large extend issues related to R\&D and the production of knowledge spillovers. Several important challenges have been the measurement of spillovers between firms, the identification of the factors that influence their generation, whether firms are able to fully take advantage of incoming spillovers and appropriate their proprietary knowledge, or whether knowledge externalities are geographically localized (see for instance Bernstein and Nadiri, 1989, Jaffe et al., 1993, Audretsch and Feldman, 1996, Cassiman and Veugelers, 2002, and Bloom et al., 2013).

In this paper, we propose to focus on the issue of the identification of spillovers in the particular case of the regulation of firms with incentive contracts (Laffont and Martimort, 2002). There are two important features in our model: First, the incentive power of each regulatory contract directly shapes the operator's R\&D intensity which is reinterpreted as the cost-reducing effort activity in our setting. Second, spillovers here are measured within the corporations (the groups) that provide public services in several urban areas simultaneously. Thus, spillovers are directly linked to the know-how of a specific corporation, but they also depend on the decisions taken by a manager locally.

We apply our framework to the French urban transport industry, which is particularly well fitted for our purpose. In each city of significant size, a local authority regulates and monitors public transport services while a single firm is in charge of the operation within a specific regulatory framework. The latter takes the form of a written contract that defines the payment and cost-reimbursement rules between the parties. Two types of regulatory contracts are available, namely fixed-price and costplus schemes, although fixed-price regimes are implemented in a very large majority of urban areas. Under fixed-price contracts, the operator receives subsidies to cover ex-ante (expected) operating deficits, and is thus provided with powerful incentives to 
reduce operating costs. Cost-plus regulation became less popular after the central government decided in 1982 that the financial responsibility of the transport operations would rest on the shoulders of local municipalities; under a cost-plus regime, subsidies are provided to finance ex-post (realized) deficits, they thus provide no incentives to transport operators to reduce costs.

A distinguishing feature of this industry is that about eighty percent of the operators are owned by three large industrial corporations. The transport services provided in different networks by operators belonging to the same industrial group are therefore, in essence, provided by the same firm. This peculiarity suggests that these companies may benefit from the exchange of information and feedback on experience across many networks operated in different localities with different characteristics. In other words, the economic activity involved in one specific network may affect the economic activity in other networks operated by the same company. In the specific context of the urban transport industry, we expect these spillovers or externalities to take place when a cost-reducing activity developed by one of the operators reaches other productive units of the group. Hence, all networks operated by the same corporation benefit from the cost-reducing efforts provided by all the members of the group. To reflect the fact that these spillovers could be related to a large array of know-how generated by the firm, ranging from technological to organizational, we will refer to them as knowledge spillovers throughout the text.

In order to be able to exploit incoming spillovers, firms need to work on their absorptive capacity. The latter depends on the level of prior related knowledge of the firm, which potentially entails basic skills, similar languages, or scientific or technological capabilities, which, in turns, confers the firm the ability to identify the value of new information and assimilate it. We therefore build and estimate a structural cost regulation model that accounts for the fact that R\&D expenditures (the effort of the operator) and absorptive capacity are directly related and allow the production of knowledge spillovers. In each given city, the operator is one of the three large industrial corporations present in France or it can be an independent local entity. In both cases, the operations are run by a local manager who decides upon the effort level to be exerted to reduce the operating costs of the local transportation activity. In networks regulated under fixed-price contracts, the operator maximizes its own profit and determines the optimal effort level. The latter depends on the local incentives, but it is also affected 
by all the other effort activities exerted by the other operators of the same group. The econometric task consists then in recovering the parameters of a static model of cost regulation, and testing for the relevance of knowledge spillovers. Our results suggest that the flow of knowledge spillovers across the members of the same group are significant and increase with the size of the group, and they allow transport operators to obtain significant cost reductions. Moreover, networks that present larger characteristics differences relative to their group benefit to a larger extent from the efforts provided in the other networks of their group. Thus, while a minimum degree of overlap of knowledge across operators is necessary for internal communication, there are also benefits to diversity of knowledge and organizational structures across networks.

Our work shares features with different strands of the empirical literature. On the one hand, our paper contributes to the recent empirical literature on incentive regulatory policies. Gagnepain and Ivaldi (2002 and 2017) and Gagnepain et al. (2013) focus on the same type of data and show that fixed-price contracts lead to a significant decrease of the operating costs of the local operators in France. Our model builds on a similar framework and assumes moreover that the technology of each local operator is not independent from the decisions of the other managers that belong the same industrial corporation. Thus, following Holmstrom (1982), we argue here that group incentives matter, although there is no monitoring from the headquarter in our framework. From that perspective, our paper is one of the first to take into account knowledge spillovers in a regulation context.

On the other hand, our paper also relates to the empirical literature on R\&D knowledge spillovers with the difference that it focuses on spillovers within firms rather than across firms. ${ }^{4}$ Most related to our paper is the work of Klette (1996), which uses data on Norwegian manufacturing firms and analyzes the interaction between firm performance and R\&D expenditures. The author evaluates $R \& D$ at the line-of-business level within each firm and also identifies firms that belong to the same interlocking group of firms, i.e., the set that includes a parent company and all subsidiaries in which the parent company owns a majority share of equity. The paper sheds light on significant spillover effects across different lines of business (e.g. chemicals or metal products) within a firm but also reveals significant spillovers for activities within a line of busi-

\footnotetext{
${ }^{4} \mathrm{~A}$ more general discussion on franchise contracts, reputation, and umbrella branding entails for instance Klein and Saft (1985), Andersson (2002), and Hakenes and Peitz (2008).
} 
ness that are carried out by different firms within the same group. Szulanski (1996) analyzes firms' ability to diffuse best practices internally. The paper suggests that the main barriers to internal knowledge transfer are knowledge-related factors such as the recipient lack of absorptive capacity. In our framework, we identify the absorptive capacity for each industrial corporation in our industry and find evidence of diffusion of knowledge spillovers across transport operators linked to the same group. In particular, we are able to construct indices that relate to the structural differences between a given network and the remaining networks from the same group. Another related example is Darr et al (1995), which analyzes knowledge transfers acquired through learning-by-doing in service organizations. The authors focus on pizza stores owned by different franchisees and find evidence of knowledge transfer across stores owned by the same franchisee but not across stores owned by different franchisees. A related issue highlighted by the literature is the importance of free-riding among the different franchisees of a given chain (see for example Brickley, 1999 and Lafontaine and Slade, 1997, 2007). A franchisee has incentives to free-ride on the tradename of the franchisor given that her effort is private while the benefits will accrue to all the members of the chain. This closely relates to our model where each local operator privately pays the cost of its effort which will be beneficial to all members of the same industrial group.

The organization of the paper is as follows: Section 2 describes the regulation of urban transportation in France in more detail. Section 3 discusses the assumptions that are maintained throughout the paper. Section 4 presents our model of cost regulation which encompasses the main features of urban transportation and the environment in which network operators make their decisions. Section 5 then develops a formal specification of the cost function to be estimated. Section 6 is devoted to the construction of the variables and the presentation of our results. Section 7 evaluates the cost gains of adding operators to a group. Section 8 provides a summary and some concluding remarks.

\section{The French Urban Transportation Industry}

As in most countries around the world, urban transportation in France is a regulated activity. Local transportation networks cover each urban area of significant size, and for each network, a local authority (a municipality, a group of municipalities or a dis- 
trict) is in charge to regulate an operator which has been selected to provide the transportation service. Regulatory rules prevent the presence of several suppliers of transportation services in the same urban network, and each network is therefore operated by a single operator. Each local authority organizes its own transportation system by setting route and fare structures, capacity, quality of service, conditions for subsidizing the service, levels of investment and ownership nature. The local authority may decide to operate the network directly or to require the services of a transport service provider. In the latter case, a formal contract defines the regulatory rules that the operator must follow as well as the cost-reimbursement scheme between the authority (the principal) and the operator (the agent).

In most urban areas, operating costs are on average twice as high as commercial revenues. Budgets are therefore rarely balanced without subsidies. One reason is that operators face universal service obligations and must operate in low demand areas. Low prices are maintained to ensure affordable access to all consumers of public transportation. Moreover, special fares are given to targeted groups like seniors and students. Subsidies come from the State's budget, the local authority's budget, and a special tax paid by local firms (employing more than nine full-time workers). They are not necessarily paid directly to the operator. In addition to the price distortions causing deficits, informational asymmetries that affect the cost side and lead to inefficiencies make it more difficult to resume these deficits.

During our period of observation, about eighty percent of local operators are private and are owned by three large companies, two of them being private while the third one is semi-public. In 2002, these companies, with their respective ownership structures and market shares (in terms of number of networks operated) were Keolis (private, 30\%), Transdev (semi-public, 19\%), and Connex (private, 25\%). In addition there are a small private association, Agir, and a few public firms controlled by local governments. Industrial groups involved in the provision of urban transport services have a long history of mergers in France. Keolis was born out of the merger of several companies created in the beginning of the 20th century. The Société des transports automobiles, created in 1908, its subsidiary (the Société générale des transports départementeaux) and the company Lesexel, founded in 1911 to help on the development of tramways, merged to form the VIA-GTI company, mainly focused on urban transport. In the meantime, another company, Cariane, was specialized in the French interurban 
transport. Ultimately, VIA-GTI and Cariane merged in 2001 to give birth to Keolis. The industrial group Connex was born out of the merger of the Compagnie Générale Française des Transports et Entreprises (CGFTE) and the Compagnie Générale d'Entreprises Automobiles (CGEA) in the late 1980's..$^{5}$ The company was ultimately renamed Veolia Transport in 2005. Finally, the Transdev group was created in 1955. On March 3rd 2011, it merged with Veolia Transport to give birth to Veolia Transdev. The overall proportion of networks operated by firms belonging to one of the three major groups is of $78.6 \%$.

Two types of regulatory contracts are available in the industry, namely fixed-price and cost-plus schemes, although fixed-price regimes are implemented in a very large majority of urban areas. Under fixed-price contracts, operators receive subsidies to finance the expected operating deficits, while under cost-plus schemes, subsidies are paid to the local authorities to finance ex-post deficits. Hence fixed-price regimes are very high-powered incentive schemes, while cost-plus regimes do not provide any incentives for cost reduction. Cost-plus regulation became less popular after the central government decided in 1982 that the financial responsibility of the transport operations would rest on the shoulders of local municipalities. We count twenty-three changes of regulatory regimes between 1987 and 2001, eighteen of them being switches from costplus to fixed-price regimes. Moreover, the automatic renewal of the contract between the local authority and the operator in place was effectively ended, by law, in 1993. Since then, local authorities are required to use beauty contests to allocate the construction and management of infrastructures of urban transportation. In practice, however, very few networks have experienced changes of operators from one regulatory period to another. Over the period covered by our analysis, only 5 networks have decided to get rid of their operators to select another company. Out of these, two changed from being operated by a firm belonging to a group to being operated by an independent firm, while only one network changed from being operated by an independent firm to being operated by a firm belonging to a group. Finally, only 2 networks saw their operator change from a firm belonging to a given group to a firm belonging to another group. As a matter of fact, by committing to distinct geographical areas, the three main groups succeeded in reducing the degree of competition in the awarding of transport operations in urban areas where the regulatory contract came to an end. Competitive tendering is therefore not a relevant issue in this sector, and ex-ante competition is not

\footnotetext{
${ }^{5}$ The company actually decided to take on the name Connex in 2000.
} 
so fierce. Finally, these groups also operate other municipal services such as water distribution or garbage collection, which makes it even harder for public authorities to credibly punish operators following bad performances in the provision of transport services. It follows that group structures are rather stable both across networks and over time in our sample.

Our objective is to take these features of the urban transport industry into account and to perform an analysis of the observed regulatory schemes within a principalagent setting. This requires a database that provides information on both the performance and the organization of the French urban transport industry. Such a database was created in the early 1980s from an annual survey conducted by the Centre d'Etude et de Recherche du Transport Urbain (CERTU, Lyon) with the support of the Groupement des Autorités Responsables du Transport (GART, Paris), a nationwide trade organization that gathers most of the local authorities in charge of a urban transport network. In France, this rich source is a unique tool for comparing observed regulatory schemes both across year and over time. In our econometric analysis, we consider the regulatory scheme adopted in each urban area during a year as a realization of the same regulatory contract. The sample does not include the largest networks of France, i.e., Paris, Lyon and Marseille, as they are not covered by the survey. Overall, the panel data set covers 67 different urban transport networks over the period 1987-2001.

\section{Delineating the Scope of the Study}

The organization and structure of the urban transportation industry in France as described above motivates the following assumptions.

Assumption 1: The expertise of the regulator is limited.

In France, local authorities have been historically blamed for their laxness in assessing operating costs, mainly because of their lack of knowledge and experience of transportation economics and technologies, and/or because of their limited capacity of monitoring and auditing complex operating activities. These considerations prevent them to adequately assess the effort of operators in providing appropriate and competent solutions to cost and network inefficiencies. 
We thus assume that the network operator has private information about its innate technology (adverse selection) and that its cost-reducing effort is non-observable (moral hazard). Because French transport authorities are politicians from the local municipal councils instead of transport professionals, their limited auditing capacities is recognized among practitioners. A powerful and well-performed audit system needs effort, time and money. French experts on urban transportation blame local authorities for being too lax in assessing operating costs, mainly because of a lack of knowledge of the technology. ${ }^{6}$ The number of buses required for a specific network, the costs incurred on each route, the fuel consumption of buses (which is highly dependent on drivers' skills), the drivers' behavior toward customers, the effect of traffic congestion on costs, are all aspects for which operators have much more data and a better understanding than public authorities. ${ }^{7}$

Assumption 2: Technological innovation may spill-over across operators of the same industrial corporation.

Innovation in public transportation is usually triggered by changes in the regulation of the service. A first well known example is the British deregulation case, which came from the Transport Act of 1985 and set the local bus service in Great Britain. A second one is the introduction of the new Passenger Transport Act 2000 in the Dutch public transport industry which decentralized the powers to provincial and regional authorities (Ongkittikul and Geerlings, 2006). The French case is quite similar as the 1982 Transportation Law was enacted to facilitate decentralized decision-making on urban transportation and to provide guidelines for regulation. Since then, each local authority organizes its own transportation system and is responsible for cost overruns in case of bad performance of the operator.

As a result, fixed-price regimes, which guarantee that the transport operator pro-

\footnotetext{
${ }^{6}$ The French urban transport expert O. Domenach has argued that "the regulator is not able of determining the number of buses which is necessary to run the network. The same comment can be made regarding the fuel consumption of each bus. The regulators are generally general practitioners instead of transport professionals. Hence, the (re)negotiation of contracts between regulators and operators is not fair. See Domenach (1987). A more recent report on the weak capabilities of expertise of the local governments and the lack of ex ante competition in the industry is proposed by the French court of auditors (Cour des Comptes) in its 2005 report.

${ }^{7}$ Gagnepain and Ivaldi (2002) confirmed through a test that adverse selection and moral hazard are two important features of the industry. They showed that a regulatory framework which encompasses these two ingredients performs well to explain the data.
} 
vides the highest possible effort level, become more popular after 1982. Providing effort is directly related to the innovation process and the R\&D activity of the firm. It is first related to the action of managers who spend time and energy in improving the location of inputs within the network (the main concern is the management of bus drivers), finding cheaper suppliers, bargaining better procurement contracts, subcontracting non-essential activities, monitoring employees, or solving potential labor conflicts. It also entails the development of a computerized information system which allows the operator to observe in real time the position of all vehicles in the network, changes in environmental friendly energy standards and propulsion systems, or trip information to travelers. Finally, the operator might negotiate with the regulator the introduction of bus priority or guided busway on specific network segments in order to improve commercial speed, or the use of smaller vehicles or low floorbus, the design of timetable and frequency, or pricing and marketing strategies. Network in different urban areas may share heterogeneous features and topology, hence the experience and innovative activity of one operator might benefit to other firms that belong to the same industrial corporation and operate transport services elsewhere.

The larger industrial groups, Keolis, Connex and Transdev, have in each network they operate a local manager who takes care of running the network and has decision rights on the effort to be exerted in order to decrease operating costs. Given this decision-making configuration, we expect actions related to cost-reducing activities taken in a specific network to generate a positive externality on the operating costs of the remaining operators of the group. The main idea is that knowledge generated in a given location can be processed by the group's headquarters and later be transmitted and used in another network operated by the group. For instance, the results of process $R \& D$ obtained in one location can spill-over to another operator through the group's headquarters. This operator would therefore benefit from (part of) this R\&D without investing as much effort as it would have to if it were independent. Similarly, the effort incurred to find a cheaper supplier in one network may reduce the need to look for a cheaper supplier in another city. The bargaining of procurement contracts may also be easier if the operator belongs to a group with relevant experience in other networks. Likewise, methods to efficiently monitor employees could also be learned in a given place and transmitted to another. In that sense, a network belonging to a group will benefit from positive externalities coming from the effort exerted in all the 
remaining networks of the group. Whether the knowledge generated in a given location is transferable or applicable to another network of the group might depend on the absorptive capacity of the firms and/or network characteristics in a sense to be defined in what follows.

We propose now to build up a structural cost function that accounts for the incentive power of the contract faced by the operator as well as for the structure of the group it belongs to, if any. This allows us to test for the relevance of knowledge spillovers among operators in the French urban transport industry. ${ }^{8}$

\section{The Economic Model}

We now present our model of regulation of the urban transport industry. Starting from the technology associated with the transportation activity, we first define the primal operating cost function, which is conditional on the cost-reducing activity of the operator. We describe how the contract types and the structure of the transport groups affect the operators' choice of cost-reducing effort. Once the optimal level of effort is determined, we plug it back into the conditional cost function to obtain the final cost function that captures all the relevant incentives affecting the activity of the firm.

\section{Technology and primal cost function}

To provide the required level of services $Q$, the transit firm (the operator) needs to combine variable and fixed inputs. Let $w=\left(w_{L}, w_{M}\right)$ be the price of variable inputs, namely labor $(L)$ and materials $(M)$. Let $K$ and $I$ be, respectively, the stock of capital and the infrastructure used by the operator, which are both fixed in the short run. The production process is then represented with the production function $Q=f(K, I, L, M \mid \lambda)$, where

\footnotetext{
${ }^{8}$ Three additional remarks should be made. First, private information on demand is not a relevant issue in our industry. Local governments are well informed about the transportation needs of citizens. The number of trips performed over a certain period is easily observed, and the regulator has a very precise idea of how the socio-demographic characteristics of a urban area fluctuate over time. Given the level of demand, the regulator sets the service capacity provided by the operator. Second, we do not address the issue of determining what should be the optimal rate-of-return on capital. The rolling stock is owned by the local government for a vast majority of networks. In this case, the regulator is responsible for renewing the vehicles, as well as guaranteeing a certain level of capital quality. Finally, we rule out the possibility of risk sharing in the contractual relationships between the operators and the regulators since the provision of transport services does not entail unpredictable cost fluctuations for the operators.
} 
$\lambda$ is a vector of parameters characterizing the technology in the production process. Note that both $L$ and $M$ are the efficient levels of inputs, which are only observable to the operator. We denote by $C$ the observed operating cost of each firm. As the stock of capital $K$ and the size of the infrastructure $I$ are determined by the regulator, our cost function is determined in the short run, and is conditional on the stock of capital and on the size of the infrastructure. ${ }^{9}$ Each operator $i$ chooses the cost-minimizing input allocation subject to technological constraints, which leads to a cost function of the following form:

$$
C_{i}^{0}=C_{i}^{0}\left(w_{i}, Q_{i}, I_{i}, K_{i} \mid \beta\right),
$$

where $\beta$ is a vector of parameters characterizing the cost function. In reality, the actual operating cost may differ from the minimum operating cost defined by (1). Inefficiencies may prevent operators from reaching the required level of service $Q$ at the minimum cost, which will result in upward distorted costs. To counterbalance these inefficiencies however, firms can undertake cost-reducing activities to which we will refer as R\&D effort.

A given firm $i$ operating a specific network can be either independent or belong to one of each of the industrial groups $g=\{$ Keolis, Transdev, Connex $\}$, which operate a set of urban networks $N_{g}=\left\{1, \ldots, n_{g}\right\}$. While production inputs are exclusively network specific, we assume the inefficiencies to affect all the $n_{g}$ networks of a given group $g$. Likewise, we expect the R\&D efforts exerted in a given network to affect the operating cost of other firms belonging to the same industrial group. These spillovers are, however, not present for an independent network. We return to these points more in details below.

Denote by $\theta_{g}$ the intrinsic inefficiency level of each of the $n_{g}$ networks of group $g$, and let $\theta$ be the intrinsic inefficiency level of an independent network. We denote the R\&D effort level of firm $i$ belonging to group $g$ as $e_{i g}$, and let $e_{-i g}$ denote the effort of the remaining networks belonging to the same group. Let $e_{i}$ be the R\&D effort level of an independent network $i$. Note that both the inefficiency and the effort levels are unobservable to the regulator and to the econometrician. Each operator therefore faces

\footnotetext{
${ }^{9}$ In practice, the operator plays a role in the choice of investment, which, potentially, introduces another dimension that can be affected by information asymmetries. Our understanding of the industry is that this question is of second-order since, for instance, the production of new buses, which could have a drastic impact on the efficiency of the transport network, takes time and refers to periods longer than regulatory periods.
} 
a cost function that defines the frontier of minimum operating costs conditional on the levels of capital, infrastructure, inefficiency, effort and group structure. Specifically, operator $i$ faces a cost function of the form:

$$
C_{i}\left(C_{i}^{0}, \theta, e \mid \beta\right)= \begin{cases}C_{i}^{0} \times \phi\left(\theta, e_{i}\right), & \text { if } i \text { is independent } \\ C_{i}^{0} \times \phi\left(\theta_{g}, e_{i g}, \kappa_{i g} e_{-i g}\right), & \text { if } i \in N_{g} .\end{cases}
$$

Here, $\phi(\theta, e)$ is a continuous function that is increasing in $\theta$ and decreasing in $e$. A direct measure of the knowledge spillovers obtained by operator $i$ is given by $\kappa_{i g} e_{-i g}$ while $\kappa_{i g}$ should be seen as the absorptive capacity of the firm. Following Cohen and Levinthal (1989 and 1990) and Kamien and Zang (2000), the absorptive capacity denotes the ability of the firm to exploit incoming spillovers. It depends on the level of prior related knowledge of the firm, which potentially entails basic skills, similar languages, or scientific or technological capabilities, which, in turns, confers the firm the ability to identify the value of new information and assimilate it. Note that these authors also claim that $R \& D$ expenditures and absorptive capacity are directly related as R\&D develops the firm's ability to identify, assimilate, and exploit incoming knowledge. In our model, firms take into account enhancement of absorptive capacity in determining their R\&D expenditure level as $e_{i g}$ depends directly on $\kappa_{i g}$. Moreover, we expect $\kappa_{i g}$ to depend both on network and group characteristics, as the networks within a same group should benefit asymmetrically from knowledge spillovers. We discuss more thoroughly the identification of $\kappa_{i g}$ in what follows.

Note finally that, while the inefficiency parameter $\theta$ is exogenous, the cost reducing effort is a choice variable which will depend on both the contract that the firm faces and on the structure of the group it belongs to, if any. We next turn to the operator's effort decision and to the construction of the structural cost function.

\section{Incentives, knowledge spillovers and the optimal level of effort}

We have already emphasized the fact that very few cost-plus contracts are used by local authorities. Moreover, we have also stressed that firms need to be active in $R \& D$ in order to be able to exploit incoming spillovers; thus, the very few operators that do not exert any effort under cost-plus regimes should be unable to benefit from the efforts of the other members of their corporation. Hence, for the sake of tractability and clarity, 
we focus in what follows on fixed-price contracts only. Under a fixed-price contract, the operator obtains an ex-ante subsidy $t$ equal to the expected balanced budget, i.e., the difference between expected costs and expected revenues. This contract is a very high-powered incentive scheme as the operator is residual claimant for effort.

Each urban network run by a corporation has a local manager in charge of the transport operations. Each manager is concerned about local profits, but the local costreducing R\&D effort can reach other networks of the same group through the group's headquarters. We make the important assumption that decisions on cost-reducing activities are sequential across the networks of the same group. In other words, the regulatory arrangements between the group headquarter and each local authority are signed through staggered contracts. ${ }^{10}$ We motivate this assumption as follows: First, network operators are not able to unilaterally decide on the objectives of a fixed-price contract as the latter is rather the outcome of a negotiation process between the operator and the local authority. Second, contract length varies from one network to another, with an average close to 6 years. Many municipalities prefer to implement even shorter regulatory arrangements, while others are more keen to use long-term regimes that can last for periods of more than 10 years. This makes it even harder for a group to synchronize decisions on the content of the contracts. Finally, note that municipal councils are elected for short period terms which do not necessarily coincide with contract schedules; a change of political color after a new election might for instance lead to a change of operator after a new tender. ${ }^{11}$ Overall, this motivates our claim that the group headquarter cannot easily anticipate all the future regulatory outcomes and that a decentralized management of contract choice and effort decisions seems to be a more reasonable assumption. However, it is in the best interest of the headquarters to build experience on local management and transmit the information to all the operators of the group.

We now explicitly take into account these incentives through the cost function (1) that is conditional on inefficiency $\theta$ and the R\&D effort level $e$. We first derive the optimal level of effort for each operator and check how this effort depends on the

\footnotetext{
${ }^{10}$ The evaluation of the relative social welfare merits of signing staggered or synchronous contracts is outside the scope of this paper. Cabral (2017) and Iossa et al. (2019) suggest that the choice of one arrangement or another should depend on whether the industry is characterized by economies of scale and whether the incumbent enjoys a significant cost advantage with respect to potential competitors.

${ }^{11}$ Gagnepain and Ivaldi (2017) sheds light on how political factors may affect the choice of regulatory contracts in the French transportation industry.
} 
incentives generated by the economic environment of the firm. Second, we plug back this level of effort into the conditional cost function. This allows us to generate an unconditional structural cost function that can be estimated with our data.

Let $N_{g}$ denote the set of networks that a group $g$ operates under a fixed-price $(F P)$ contract, which entails card $\left(N_{g}\right)=n_{g}$ networks. Under a fixed-price contract, each operator $i$ determines the optimal R\&D effort level that maximizes the objective function

$$
\pi_{i}= \begin{cases}t_{i}+R\left(q_{i}\right)-C_{i}\left(C_{i}^{0}, \theta, e_{i} \mid \beta\right)-\psi\left(e_{i}, \alpha\right) & \text { if } i \text { is independent, } \\ t_{i}+R\left(q_{i}\right)-C_{i}\left(C_{i}^{0}, \theta_{g}, e_{i g}, \kappa_{i g} e_{-i g} \mid \beta\right)-\psi\left(e_{i g}, \alpha\right) & \text { if } i \in N_{g},\end{cases}
$$

where $R(q)=p(q) q$ denotes revenue, $q$ measures transport demand, and the cost reduction activity $e_{i}$ induces an internal cost $\psi\left(e_{i}\right)$ which is borne solely by the local operator. $^{12}$ If the operator is independent, the optimal effort level $e_{i}$ that maximizes its profit in (3) is determined by the following first order condition:

$$
-\frac{\partial C_{i}\left(C_{i}^{0}, \theta, e_{i} \mid \beta\right)}{\partial e_{i}}=\frac{\partial \psi_{i}\left(e_{i}, \alpha\right)}{\partial e_{i}}
$$

which implies that the optimal level of effort $e_{i}$ is chosen to equalize marginal cost savings with the marginal disutility of effort. In the case of a firm that belongs to a group, the optimal R\&D effort level is also influenced by the R\&D effort exerted by the remaining members of the group. Each of the operator of group $g$ regulated under a $F P$ contract takes $e_{-i g}$ as given and chooses the optimal $e_{i g}$ that satisfies the first order conditions:

$$
-\frac{\partial C_{i}\left(C_{i}^{0}, \theta_{g}, e_{i g}, e_{-i g} \mid \beta\right)}{\partial e_{i g}}=\frac{\partial \psi_{i}\left(e_{i g}, \alpha\right)}{\partial e_{i g}}, \quad \forall i \in N_{g}
$$

Hence, the optimal effort level $e_{i g}$ is conditional on the effort $e_{-i g}$ exerted by the other members of the group:

$$
e_{i g}=e_{i g}\left(C_{i}^{0}, \theta_{g}, \kappa_{i g} e_{-i g} \mid \beta, \alpha\right), \quad \forall i \in N_{g}
$$

\footnotetext{
${ }^{12}$ We distinguish capacity (or supply) $Q$ from demand $q$. As demand fluctuates during the day, the regulator determines the minimum capacity level that covers all quantities of service requested at any moment of the day. As capacity cannot adjust instantaneously to demand levels, the minimum capacity level is always higher than demand. With these notations, commercial revenues are determined by $q$, while costs are determined by $Q$.
} 
We expect $e_{i g}$ to be decreasing in the effort of the others $e_{-i g}$. Free-riding naturally arises because the cost of effort is only borne by the local network operator while the effort itself benefits (at least partially) all members of the group. Solving for the $n_{g}$ equations, we obtain the unconditional effort level:

$$
e_{i g}=e_{i g}\left(C_{i}^{0}, C_{-i}^{0}, \theta_{g}, \kappa_{i g}, n_{g} \mid \beta, \alpha\right), \quad \forall i \in N_{g}
$$

Plugging these effort level back into the conditional cost function (2) yields the unconditional cost function.

\section{Econometric specification}

We now turn to the econometric specification of our cost regulation framework. In order to derive the structural cost function to be estimated, we need to assume a specific functional form for the cost function in (2) and the disutility of effort $\psi\left(e_{i}\right)$. We assume a Cobb-Douglas specification for the cost function. This specification retains the main properties desirable for a cost function while remaining tractable. Alternative more flexible specifications such as the translog function lead to cumbersome computations of the first order conditions when effort is unobservable. The primal cost expression is therefore specified as:

$$
C_{i}^{0}=C_{i}^{0}\left(w_{i}, Q_{i}, I_{i}, K_{i} \mid \beta\right)=\beta_{0} w_{L_{i}}^{\beta_{L}} w_{M_{i}}^{\beta_{M}} Q_{i}^{\beta_{Q}} I_{i}^{\beta_{I}} K_{i}^{\beta_{K}}
$$

We impose homogeneity of degree one in input prices, i.e. $\beta_{L}+\beta_{M}=1$. In order to allow the observed cost $C$ to deviate from the cost frontier defined by (8), we specify the function $\phi(\cdot)$ to be the exponential function, so that (2) is now specified as

$$
C_{i}\left(C_{i}^{0}, \theta, e \mid \beta\right)= \begin{cases}C_{i}^{0} \times \exp \left\{\theta-e_{i}\right\} & \text { if } i \text { is independent } \\ C_{i}^{0} \times \exp \left\{\theta_{g}-e_{i g}-\kappa_{i g} \sum_{j \neq i} e_{j g}\right\} & \text { if } i, j \in N_{g} .\end{cases}
$$

We assume the internal cost of effort to be provided by the following function:

$$
\psi\left(e_{i}\right)=\exp \left\{\alpha e_{i}\right\}-1, \quad \alpha>0
$$


where $\alpha$ is a parameter to be estimated.

Using the specifications for the operating costs (9) and the cost of effort (10), we can solve the first order conditions defined in the previous section to express the optimal effort level for a network under a FP contract. We next determine the effort levels and the resulting unconditional cost functions for the different operators according to their group status.

\section{Independent Networks}

For an independent network $i$, the optimal R\&D effort level under a $F P$ contract is given by the solution to (4) and is expressed as:

$$
e_{i}=\frac{1}{1+\alpha}\left(\ln \left(C_{i}^{0}\right)-\ln (\alpha)+\theta\right)
$$

Substituting back $e_{i}$ into (9) allows us to obtain the final form for the cost function $C_{i}(\cdot)$ to be estimated for independent networks as:

$$
\ln \left(C_{i}\right)=\frac{\alpha}{1+\alpha}\left[\ln \left(C_{i}^{0}\right)+\theta\right]+\frac{1}{1+\alpha} \ln (\alpha)
$$

\section{Operators Belong to Industrial Groups}

If a network $i$ belongs to a group and is under a $F P$ contract, it will benefit from its own cost reducing activity and from the efforts of the $n_{g}-1$ remaining operators that belong to the same group and that are regulated under a fixed-price regimes as well. Thus, for any industrial group $g$ where $n_{g} \geq 2$ and for any $i, j \in N_{g}$ :

$$
\begin{aligned}
e_{i g}= & \frac{1}{\left(1+\alpha+\left(n_{g}-1\right) \kappa_{i g}\right)} \times\left[\frac{\left(1+\alpha+\left(n_{g}-2\right) \kappa_{i g}\right)}{\left(1+\alpha-\kappa_{i g}\right)} \ln \left(C_{i}^{0}\right)\right. \\
& \left.-\frac{\kappa_{i g}}{\left(1+\alpha-\kappa_{i g}\right)} \sum_{j \neq i} \ln \left(C_{j}^{0}\right)+\left(\theta_{g}-\ln (\alpha)\right)\right]
\end{aligned}
$$

Notice how, for firm $i, e_{i g}$ now depends on the components defining the cost ingredients of the remaining networks of the group, $\sum_{j \neq i} \ln C_{j}^{0}$. A higher effort $e_{i g}$ is expected if 
the firm faces a higher cost $C_{i}^{0}$, which happens for instance in the case of higher input prices $w_{i}$. At the same time, shirking by $i$ is likely if the other members of the same group also face high costs $C_{j}^{0}$, i.e., if they exert a significant amount of R\&D effort as well. Plugging the optimal efforts (13) back into the cost function (9) allows us to obtain the final form for the cost functions $C_{i g}(\cdot)$ to be estimated. Hence if operator $i$ is under a FP contract and belongs to a group $g$ where $n_{g}^{f p} \geq 2$, then, $\forall j \in N_{g}$, the final form for the cost function is given by:

$$
\begin{aligned}
\ln \left(C_{i g}\right)= & \frac{\alpha}{\left(1+\alpha+\left(n_{g}-1\right) \kappa_{i g}\right)}\left[\frac{\left(1+\alpha+\left(n_{g}-2\right) \kappa_{i g}\right)}{\left(1+\alpha-\kappa_{i g}\right)} \ln \left(C_{i}^{0}\right)\right. \\
& \left.-\frac{\kappa_{i g}}{\left(1+\alpha-\kappa_{i g}\right)} \sum_{j \neq i} \ln \left(C_{j}^{0}\right)+\theta_{g}\right]+\frac{1+\left(n_{g}-1\right) \kappa_{i g}}{1+\alpha+\left(n_{g}-1\right) \kappa_{i g}} \ln (\alpha) .
\end{aligned}
$$

The absorptive capacity parameter $\kappa_{i g}$ plays a key role in this expression. As $\kappa_{i g}$ increases, the efforts provided in the remaining networks of the group have a stronger impact on the reduction of the inefficiencies. The coefficient on the $\theta_{g}$ parameter decreases in $\kappa_{i g}: \frac{\partial}{\partial \kappa_{i g}}\left[\frac{\alpha}{1+\alpha+\left(n_{g}^{f p}-1\right) \kappa_{i g}}\right]<0$. Likewise, the negative effect of the inefficiency parameter is reduced when the number of FP networks within the group, $n_{g}$, increases, as operator $i$ can benefit from the efforts of a larger number of operators. Note also that $\lim _{\kappa_{i g} \rightarrow 0} \ln \left(C_{i g}\right)=\ln \left(C_{i}\right)$, as network $i$ only benefits from its own efforts when knowledge spillovers are absent.

\section{Absorptive capacity}

We need now to discuss how the identification of the absorptive capacity parameter $\kappa_{i g}$ unfolds. We suggested above that firms should have in-house knowledge power in order to optimally benefit from R\&D spillovers. The knowledge base of each firm is proxied here by a set of variables that account for the characteristics of the transport operator, those of the network where the service is provided, and the identity of the group $g$ who owns the operator. In other words:

$$
\kappa_{i g}=\kappa\left(\gamma_{g}, \delta_{i}, D I F_{i-g}^{x}\right),
$$

where $\gamma_{g}$ is a group fixed effect which controls for the unobserved group know-how; it measures group $g$ 's contribution to the network's capacity to assimilate the knowledge 
spilled over by the other networks from the group. and $\delta_{i}$ should be seen as a variable that captures the effect of the unobserved network-specific characteristics on $\kappa_{i g}$.

Moreover, $D I F_{i-g}^{x}$ is an index which assesses potential differences in characteristic $x$ between firm $i$ and the average firm of group $g$ (regulated under a FP contract). We thus assume that the different operators of group $g$ enjoy asymmetric absorptive capacity levels. Whether information flows more easily when the features of their operations are more similar or dissimilar is unclear at this stage. Indeed, as noted by Cohen and Levinthal (1990), on the one hand "learning is cumulative, and learning performance is greatest when the object of learning is related to what is already known. As a result, learning is more difficult in novel domains"; on the other hand, "Diversity of knowledge (also) plays an important role. [...] A diverse background provides a more robust basis for learning because it increases the prospect that incoming information will relate to what is already known." Hence, the sign of the effect of $D I F_{i-g}^{x}$ on $\kappa_{i g}$ needs to be tested empirically with our data. We present now our database, the construction of the variables, and the estimation results of the empirical analysis.

\section{Data and Empirical Results}

For a network $i$ in period $t$, we estimate the cost function:

$$
\ln \left(C_{i t}\right)=\xi_{i t}^{G} \ln \left(C_{i g t}\right)+\xi_{i t}^{I} \ln \left(C_{i t}\right)+\varepsilon_{i t},
$$

where $\xi_{i t}^{G}$ takes value 1 if operator $i$ belongs to one of the three main industrial groups, and 0 otherwise, while $\xi_{i t}^{I}$ takes value 1 if operator $i$ is independent, and 0 otherwise. The error term $\varepsilon_{i t}$ accounts for potential measurement errors and is distributed according to a normal density function with mean 0 and variance $\sigma_{\varepsilon}^{2}$. Before presenting the maximum likelihood estimates of the structural cost function (16), we discuss the construction of the variables of the model.

\subsection{Data and Variables}

Different types of variables are required in order to identify our model. The cost equation calls for covariates that capture elements of the economic environment, which en- 
tails both group-specific and network-specific characteristics. Summary statistics are provided in table 1, where we distinguish operators according to their group affiliation. The table illustrates well the fact that independent operators are usually involved in smaller operations compared to those owned by large groups.

Estimating the Cobb-Douglas cost function requires information on the level of operating costs, the quantity of output, capital, and the input prices. Total costs $C$ are defined as the sum of labor and material costs. Output $Q$ is measured as the number of seat-kilometers, i.e., the number of seats available in all components of rolling stock times the total number of kilometers traveled on all routes. This measure accounts for the length of the network, the frequency of the service and the size of the fleet. It is also meant to be a measure of the quality of service. Capital $K$, which plays the role of a fixed input in our short-run cost function, is measured by the size of the rolling stock, which is the total number of seats available. Infrastructure $I$, which also plays the role of a fixed input, is measured by the total length of the transport network in kilometers. Since the authority owns the capital, the operators do not incur capital costs. The average wage rate $w_{l}$ is obtained by dividing total labor costs by the annual number of employees. The price of materials $w_{m}$ has been constructed as the average fuel price for France (published by the OECD).

We also need information on the features of the urban networks and the industrial groups in charge of the transport operations. We construct a dummy variable for each specific network and another dummy for each one of the three industrial groups (Connex, Keolis and Transdev). In order to take into account the fact that different operators from the same group may enjoy asymmetric absorptive capacities, we expect the index $D I F_{i-g}^{x}$ to be a measure of the difference in the $x$ characteristic between the observed firm $i$ and the average firm under a $F P$ contract in group $g, \bar{x}_{g}$ :

$$
D I F_{i-g}^{x}=\frac{\left|x_{i g}-\bar{x}_{g}\right|}{x_{i g}}
$$

In our estimations, we consider different dimensions $x$ in order to calculate this index. In particular, we will focus on structural differences with respect to the share of drivers and the length of the network. The share of drivers is obtained by dividing the number of drivers in each network by the total labor force. The latter includes both the bus drivers and the engineers who are responsible for the improvement of 
the operator's productivity. The size of the network is measured as the total length of the transport network in kilometers. This variable is also a proxy for the size of the operator. Again, the sample that we use in our estimation is an unbalanced panel composed of 67 different networks regulated under FP contracts and contains 714 observations over the period 1987-2001.

\subsection{Results}

We turn now to the empirical results of our estimations. Table 2 displays the estimates of two alternative specifications, where different explanatory variables are used as proxies for $\kappa_{i g}$, the firm-specific absorptive capacity within each of the industrial groups. We assume a quadratic form for $\kappa$ in (15):

$$
\kappa_{i g}=\left(\gamma_{g}+\delta_{i}+\mu D I F_{i-g}^{x}\right)^{2} .
$$

In order to compute the structural difference $D I F_{i-g}^{x}$ between a given firm and the average firm under a $F P$ contract in the group, we focus on two dimensions which are size of the network measured a the total length in kilometers (Specification I) and the share of drivers (specification II). On the one hand, network size is an important network feature as it affects the intensity of transport operations in terms of the number of seat-kilometers supplied by the firm, the technology in use (returns to scale and density are important issues in the transportation industry), and external costs as negative externalities produced by private vehicles are more important in larger cities. On the other hand, the share of drivers (around seventy percent of all workers in the average firm) provides a measure for the endowment of skills embodied in the firm. Workers in the firm are mostly drivers and engineers; engineers are generally responsible for research and development in quality control, maintenance, and efficiency. Their action is particularly important for the improvement of the average speed of the network, which can be considered as one of the most important criterion of modal choice. Improving the commercial speed of transit systems by providing specific infrastructure improvements such as lanes dedicated to buses increasingly concerns transport operators and local authorities. ${ }^{13}$

\footnotetext{
${ }^{13}$ The share of drivers could also be a good indicator of the intensity of moral hazard in the contractual relationships between the local regulator and the transport operator. Moral hazard becomes particularly
} 
Most parameters are consistent across each specification; they are usually significant at the $1 \%$ level and have the expected sign. The technological process is characterized by constant returns to scale as $\beta_{Q}$ is not statistically different from 1 . More importantly, $D I F_{i-g}^{L e n}$ and $D I F_{i-g}^{D r i}$ both have a positive impact on the absorptive capacity $\kappa_{i g}$ of the firm. This result suggests that networks that present larger characteristics differences relative to their group benefit to a larger extent from the efforts provided in the other networks from their group. Thus, while a minimum degree of overlap of knowledge across operators is necessary for internal communication, there are also benefits to diversity of knowledge and organizational structures across networks. This also goes in line with Simon (1985) which emphasizes that diverse knowledge experiences elicit the sort of learning and problem solving that yields innovation. It is key for the industrial groups in charge of transportation services in France to develop an active network of external relationships in order to strengthen each local managers' awareness of others' expertise. As a result, the group's absorptive capacity is increased.

We also estimate each network's intrinsic inefficiency $\theta_{g}$. It is group-specific when the observed transport services are run by one of the three large transport groups. Each group's know-how entails the activity of the group's engineers who are responsible for R\&D, quality control, maintenance, and network design locally. Our estimation results suggest that the group dummy variables $\theta_{g}$ are positive and highly significant. In both cases, Keolis appears to be the most efficient group (the one with the lowest $\theta_{g}$ ), followed by Connex and Transdev.

With these estimates $\hat{\mu}$ and the individual $\hat{\gamma}_{g}$ and $\hat{\delta}_{i}$ in hands, we are able to derive an evaluation of $\hat{\kappa}_{i g}$ for each industrial group. Table 3 presents the results derived from each of our specifications. The estimated $\hat{\kappa}_{i g}$ s are statistically significant and differ across groups, with larger values for Connex and Transdev. It is interesting to note that these two groups are the ones with the largest networks of municipalities regulated under FP contracts in France. As suggested by Cohen and Levinthal (1990), an organization's absorptive capacity builds on the development of the absorptive capacities of its local operators and tends to develop cumulatively. Hence, the larger the set of local networks operated by the same group, the higher the aggregated absorptive capacity.

relevant in a firm where drivers represent a large share of the working force since, in this case, the training of employees and the bargaining process with the unions become a key issue. 


\section{Simulations}

Our model predicts that operator $i$ of group $g$ will benefit from the efforts exerted by the other firms in the group, conditional on the absorptive capacity $\kappa_{i g}$. We propose now a counterfactual exercise which aims at appraising the total cost reduction effect of adding extra operators to a group. The simulation exercise works as follows:

1. For each group $g$, we calculate the average absorptive capacity $\bar{\kappa}_{g}=\frac{1}{n_{g}} \sum_{i \in g} \hat{\kappa}_{i g}$, $g=\{$ Connex, Keolis, Transdev $\}$

2. The average operator of group $g$ has average characteristics $C_{g}^{0}(\bar{w}, \bar{Q}, \bar{I}, \bar{K} \mid \hat{\beta})$ and $\bar{\kappa}_{g}$.

3. For each group $g$, we compute costs differentials which depend on the number of average operators included in the group. The simplest structure possible is the one where $g$ contains only one average firm with operating cost given by (12). Increasing the size of the group $g$ by $p$ units consists in introducing $p$ additional average operators with the same characteristics as the ones defined in 2; the individual cost beard by the $1+p$ operators in $g$ is given by the cost expression (14). Our final aim is to compute, for each group $g$, the cost differential in percentage associated with the increase in the group size from $n_{0}$ to $n_{0}+p$ average operators, $n_{0} \geqslant 1$, and $p>n_{0}$. In other words, we calculate for each group $g$ :

$$
\triangle_{n_{0}}^{p} C_{g} \equiv \frac{\left(C_{g} \mid n_{g}=n_{0}+p\right)-\left(C_{g} \mid n_{g}=n_{0}\right)}{\left(C_{g} \mid n_{g}=n_{0}\right)} \times 100 .
$$

Tables 4 to 6 present the results of this simulation exercise for Connex, Keolis, and Transdev, respectively, using the estimates of specification II. Several interesting results are worth noticing. First, most cost reductions presented in these tables are statistically significant; being in a group of at least two operators yields a higher cost reduction compared to a situation where both firms remain independent. Second, as expected, costs reductions increase with the number of participants in each group and can be quite important: An isolated Keolis operator joining a group of ten other operators would reduce costs by $12.48 \%$. Third, the marginal cost reduction decreases in the size of the group. Take the case of Keolis for instance: Switching from one to two participants allows each group member to reduce their costs by $1.62 \%$ each; at the 
same time, switching from nine to ten participants allows a $1.5 \%$ cost reduction for each of them. Finally, each group benefits from the inclusion of additional operators to different extents, conditional on their absorptive capacity. Table 3 indicates that Connex and Transdev enjoy the largest absorptive capacities, which allows them to obtain higher cost reductions compared to Keolis.

Interestingly, the last important merger that was witnessed in the French transport industry occurred in 2011 and involved precisely Connex (renamed Veolia Transport) and Transdev. Simulating the effect of this merger in terms of cost reductions is out of the scope of this paper given that the merger period does not coincide with our data, but our model provides a potential insight of this effect: As Connex is the group that enjoys the highest absorptive capacity, and Transdev is the group with the largest number of networks, Connex may be the largest recipient of the merger operation. Note also that the usual merger simulation exercise sheds light on the trade-off between a potential cost reduction after the merger and a price increase due to less ex ante competition. While previous papers working on this issue have mostly discussed the demand side of the analysis (Davis and Garcés, 2009), our model is a potential contribution to the cost side. Our results emphasize that, in network industries where the same firm operates several services simultaneously, cost savings are potentially important.

\section{Conclusion}

In this paper we identify and evaluate the presence of knowledge spillovers that flow across French urban transport operators. We take advantage of a specific feature of the industry which is that most of the operators that provide the transport services locally are owned by three large industrial groups. Thus, the same firms are present simultaneously in several urban networks, which allows them to build their know-how at the group level based on their own local expertise. We build and estimate a structural cost regulation model with asymmetric information that includes operators' individual efficiency plus their absorptive capacity which conditions their ability to process incoming information and experience from other networks. Our results suggest that the flow of knowledge spillovers across the members of the same group are significant and increase with the size of the group, and they allow transport operators to obtain significant cost reductions. 
The economic literature is almost unanimous on the fact that the incentive power of the contracts used by public authorities in charge of the organization of public services has a significant effect on the operators' costs (Gagnepain and Ivaldi, 2020). In particular, fixed-price contracts, which entail the highest possible incentive power are the ones that encourage operators to reduce their operating costs the most. This current article suggests that combining the cost-reducing activities of several firms regulated under fixed-price contract allows them to enjoy even stronger cost-reductions, compared to an industrial organization where the exchange of information is absent. Hence, fixedprice contracts are efficient tools for cost efficiency, and it is even more important to implement them in different networks at the same time in order to benefit from knowledge spillovers.

As suggested for instance by Kamien and Zang (2000), the ability of firms to be able to coordinate the type of R\&D performed by their local units is an important issue. When the local operators cannot cooperate in setting their own R\&D budgets they choose heterogeneous R\&D strategies that diminish the level of positive externality their R\&D efforts provide their rival. From a social point of view, it is then probably in the interest of the central government to promote the implementation of fixed price contracts in the French transport industry and guarantee a significant market power to transport groups in order to allow them to be present in several networks and enjoy flows of spillovers across those networks. Whether a more concentrated industry guarantees sufficient efficiency gains to the firms in order to offset the loss of competition remains to be tested. Finally, another potentially interesting issue to be tested is whether local tenders should be organized at the same time in the whole industry. Currently, local governments and operators negotiate regulatory objectives through staggered contracts, which does not facilitate the ability of the headquarters to coordinate local decisions on R\&D expenditures. Empirical evidence showing that simultaneous tenders are welfare improving would probably argue again in favor of the establishment of a national transport regulator with enough expertise in France. 


\section{References}

Andersson, F. (2002). Pooling reputations. International Journal of Industrial Organization, 20(5), 715-730.

Audretsch, D. B., \& Feldman, M. P. (1996). R\&D spillovers and the geography of innovation and production. American economic review, 86(3), 630-640.

Bernstein, Jeffrey and M. Ishaq Nadiri. "Research and Development and Intraindustry Spillovers: An Empirical Application of Dynamic Duality." Review of Economic Studies 56 (1989), 249-269

Bloom, N., Schankerman, M. and Van Reenen, J. “Identifying Technology Spillovers and Product Market Rivalry.” Econometrica vol. 81(4) (2013), pp. 1347-1393, 07.

Brickley, J. A. “Incentive Conflicts and Contractual Restraints: Evidence from Franchising" Journal of Law and Economics Vol. 42, No. 2 (1999), pp. 745-774.

Cabral, L. (2014). Staggered Contracts, Market Power, and Welfare.

Cassiman, B., \& Veugelers, R. (2002). R\&D cooperation and spillovers: some empirical evidence from Belgium. American Economic Review, 92(4), 1169-1184.

Cohen, W. M., \& Levinthal, D. A. (1989). Innovation and learning: the two faces of R \& D. The economic journal, 99(397), 569-596.

Cohen, W. M., \& Levinthal, D. A. (1990). Absorptive capacity: A new perspective on learning and innovation. Administrative science quarterly, 128-152.

Cour de Comptes. “Les transports publics urbains: rapport au président de la république suivi des réponses des administrations et des organismes intéressés", April 2005.

Darr, E.D., Argote, L. and Epple, D. “The Acquisition, Transfer, and Depreciation of Knowledge in Service Organizations: Productivity in Franchises" Management Science Vol. 41 (1995), No. 11, pp. 1750-1762.

Davis, P., \& Garcés, E. (2009). Quantitative techniques for competition and antitrust analysis. Princeton University Press.

Domenach, O., "Métamorphose des rapports contractuels dans les transports publics urbains," Transports, 326, 1987. 
Gagnepain, P. and Ivaldi, M. "Incentive Regulatory policies: The Case of Public Transit Systems in France." Rand Journal of Economics, Vol. 33 (2002), pp. 605-629.

Gagnepain, P., and Ivaldi, M. “Economic efficiency and political capture in public service contracts." Journal of Industrial Economics, 65 (2017), 1-38.

Gagnepain, P., and Ivaldi, M. (2020). Contract Efficiency in Public Transport Services. Planned for publication in the Encyclopedia of Transport edited by Roger Vickerman, Elsevier.

Gagnepain, P., Ivaldi, M., and Martimort, D. "The cost of contract renegotiation: Evidence from the local public sector." American Economic Review 103.6 (2013): 235283.

Grossman, G. M., \& Helpman, E. (1991). Innovation and growth in the global economy. MIT press.

Hakenes, H., \& Peitz, M. (2008). Umbrella branding and the provision of quality. International Journal of Industrial Organization, 26(2), 546-556.

Holmstrom, B. (1982). Moral hazard in teams. The Bell Journal of Economics, 324340.

Iossa, E., Rey, P., \& Waterson, M. (2019). Organizing Competition for the Market.

Jaffe, A. B. (1986). Technological Opportunity and Spillovers of R\&D: Evidence from Firms' Patents, Profits, and Market Value. American Economic Review, 76(5), 984-1001.

Jaffe, A. B., Trajtenberg, M., \& Henderson, R. (1993). Geographic localization of knowledge spillovers as evidenced by patent citations. the Quarterly journal of Economics, 108(3), 577-598.

Kamien, M. I., \& Zang, I. (2000). Meet me halfway: research joint ventures and absorptive capacity. International journal of industrial organization, 18(7), 995-1012.

Klette, TJ. "R\&D, Scope Economies, and Plant Performance" Rand Journal of Economics , Vol. 27 (1996), pp. 502-522.

Klein, B., \& Saft, L. F. (1985). The law and economics of franchise tying contracts. The Journal of Law and Economics, 28(2), 345-361. 
Laffont, J. J., \& Martimort, D. (2002). The theory of incentives: the principal-agent model. Princeton university press.

Lafontaine, F., and Slade, M. “Vertical Integration and Firm Boundaries: The Evidence" Journal of Economic Literature, 45(3): 629-685 (2007).

Lafontaine, F., and Slade, M. "Retail Contracting: Theory and Practice Francine" Journal of Industrial Economics Vol. 45, No. 1 (1997), pp. 1-25

Ongkittikul, S., \& Geerlings, H. (2006). Opportunities for innovation in public transport: Effects of regulatory reforms on innovative capabilities. Transport Policy, 13(4), 283-293.

Romer, P. M. (1990). Endogenous technological change. Journal of political Economy, 98(5, Part 2), S71-S102.

Simon, H. A. (1985). What we know about the creative process. Frontiers in creative and innovative management, 4, 3-22.

Szulanski G. "Exploring internal stickiness: impediments to the transfer of best practice within the firm." Strategic Management Journal 17: 27-43 (1996). 
Table 1: Summary statistics by type of operator (1987-2001)

\begin{tabular}{lccccc} 
& & \multicolumn{3}{c}{ Type of operator } \\
\cline { 3 - 6 } & & Belongs to group & \multicolumn{2}{c}{ Independent } \\
\hline Name & Variable & Mean & Std dev. & Mean & Std dev. \\
\hline Rest (Euros) & $C$ & $18,157.23$ & $26,883.30$ & $6,473.55$ & $5,261.45$ \\
Production (Seat-kilometers) & $R(q)$ & $8,400.05$ & $13,322.25$ & $2,765.65$ & $2,299.52$ \\
Wage (Euros) & $Q$ & $579,178.70$ & $748,774.50$ & $240,941.80$ & $181,420.00$ \\
Price of materials (Index) & $w_{L}$ & 29.66 & 5.72 & 29.11 & 6.36 \\
Size of the network (Kil.) & $w_{M}$ & 1.17 & 0.20 & 1.18 & 0.20 \\
\% of drivers in the labor force & Dength & 256.05 & 223.84 & 153.51 & 87.49 \\
\hline
\end{tabular}

Note: Group refer to operators belonging to either Keolis, Transdev or Connex. 
Table 2: Structural Estimation Results

\begin{tabular}{|c|c|c|c|}
\hline Name & Parameter & I & II \\
\hline Constant & & $\begin{array}{c}-3.648^{* * *} \\
(0.112)\end{array}$ & $\begin{array}{c}-3.684^{* * *} \\
(0.109)\end{array}$ \\
\hline Connex & $\theta_{\text {Connex }}$ & $\begin{array}{c}0.545^{* * *} \\
(0.063)\end{array}$ & $\begin{array}{c}0.522^{* * *} \\
(0.052)\end{array}$ \\
\hline Keolis & $\theta_{\text {Keolis }}$ & $\begin{array}{c}0.418^{* * *} \\
(0.044)\end{array}$ & $\begin{array}{c}0.374^{* * *} \\
(0.046)\end{array}$ \\
\hline Transdev & $\theta_{\text {Transdev }}$ & $\begin{array}{c}0.630^{* * *} \\
(0.057)\end{array}$ & $\begin{array}{c}0.607^{* * *} \\
(0.053)\end{array}$ \\
\hline Wage & $\beta_{L}$ & $\begin{array}{c}0.279^{* * *} \\
(0.041)\end{array}$ & $\begin{array}{c}0.273^{* * *} \\
(0.034)\end{array}$ \\
\hline Production & $\beta_{Q}$ & $\begin{array}{c}1.042^{* * *} \\
(0.199)\end{array}$ & $\begin{array}{c}1.059^{* * *} \\
(0.148)\end{array}$ \\
\hline Infrastructure & $\beta_{I}$ & $\begin{array}{c}0.124^{* * *} \\
(0.023)\end{array}$ & $\begin{array}{l}0.145^{* *} \\
(0.021)\end{array}$ \\
\hline Cost of effort & $\ln (\alpha)$ & $\begin{array}{c}1.719^{*} \\
(1.050)\end{array}$ & $\begin{array}{l}1.624^{* *} \\
(0.708)\end{array}$ \\
\hline Connex & $\gamma_{\text {Connex }}$ & $\begin{array}{c}-0.242^{* *} \\
(0.112)\end{array}$ & $\begin{array}{c}-0.225^{* * *} \\
(0.070)\end{array}$ \\
\hline Keolis & $\gamma_{\text {Keolis }}$ & $\begin{array}{c}-0.119^{*} \\
(0.069)\end{array}$ & $\begin{array}{c}-0.068^{* *} \\
(0.031)\end{array}$ \\
\hline Trans & $\gamma_{\text {Trans }}$ & $\begin{array}{l}-0.121 \\
(0.074)\end{array}$ & $\begin{array}{l}-0.076^{*} \\
(0.039)\end{array}$ \\
\hline Dif Length & $D I F_{i-g}^{L e n}$ & $\begin{array}{l}0.008^{* *} \\
(0.003)\end{array}$ & \\
\hline Dif Drivers & $D I F_{i-g}^{D r i}$ & & $\begin{array}{c}0.072^{* * *} \\
(0.024)\end{array}$ \\
\hline Stand. Dev. error & $\sigma_{\epsilon}$ & $\begin{array}{c}0.102^{* * *} \\
(0.003)\end{array}$ & $\begin{array}{c}0.104^{* * *} \\
(0.003)\end{array}$ \\
\hline Firms fixed effects & $\delta_{i}$ & yes & yes \\
\hline Number of observations & & 714 & 714 \\
\hline
\end{tabular}


Table 3: Average Knowledge Spillovers by Group

Specification

\begin{tabular}{lcc} 
& \multicolumn{2}{c}{ Specification } \\
\hline \multirow{2}{*}{ Group } & I & II \\
\hline \multirow{2}{*}{ Connex } & 0.017 & 0.015 \\
& $(0.001)$ & $(0.001)$ \\
Keolis & 0.007 & 0.005 \\
& $(0.000)$ & $(0.000)$ \\
Transdev & 0.014 & 0.012 \\
& $(0.000)$ & $(0.000)$ \\
& &
\end{tabular}

Note: Each cell represents the average knowledge spillovers of the corresponding group, computed as $\bar{\kappa}_{g}=\frac{1}{n_{g}} \sum_{i \in g} \hat{\kappa}_{i g}$. Standard errors are in parenthesis. 


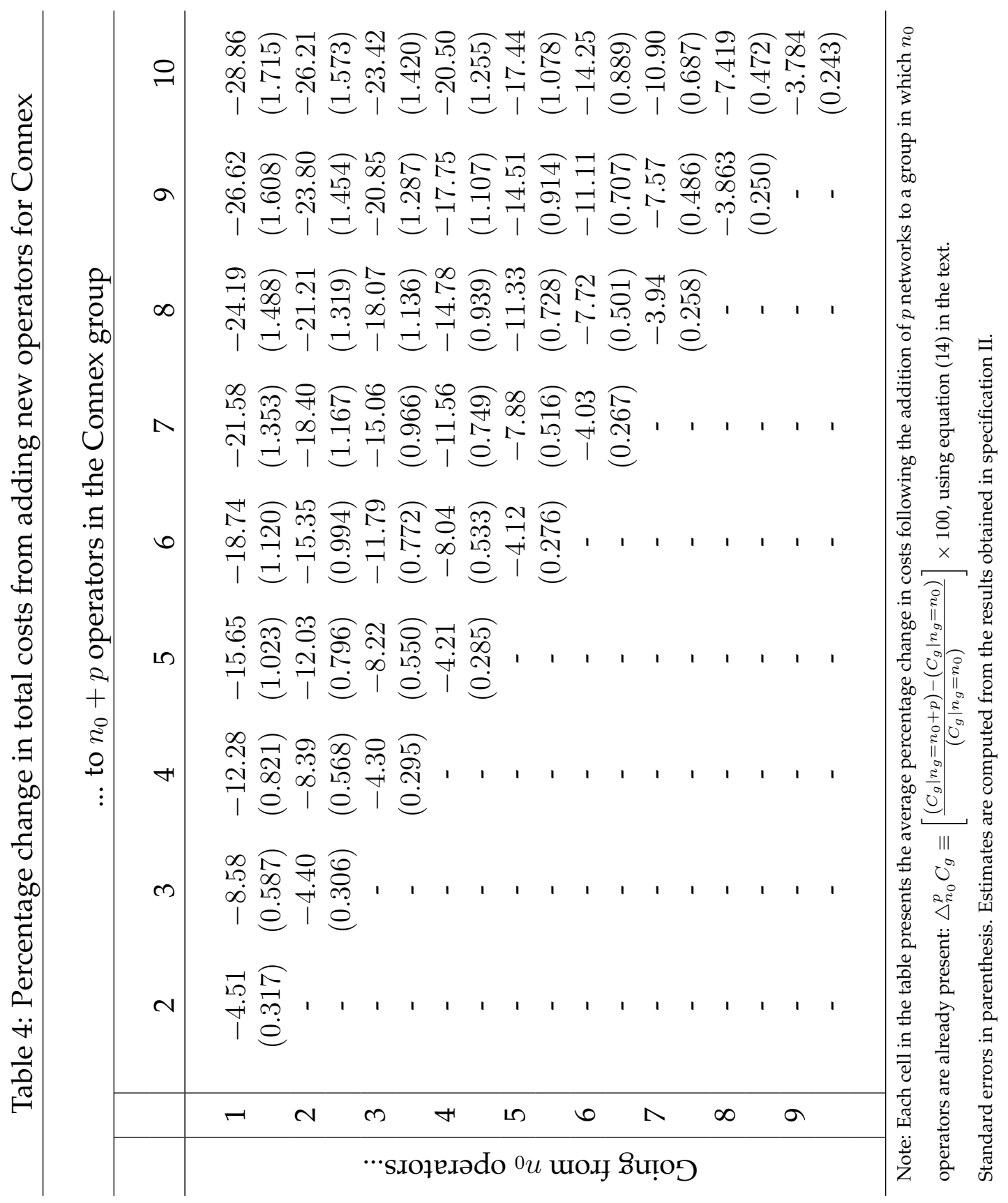




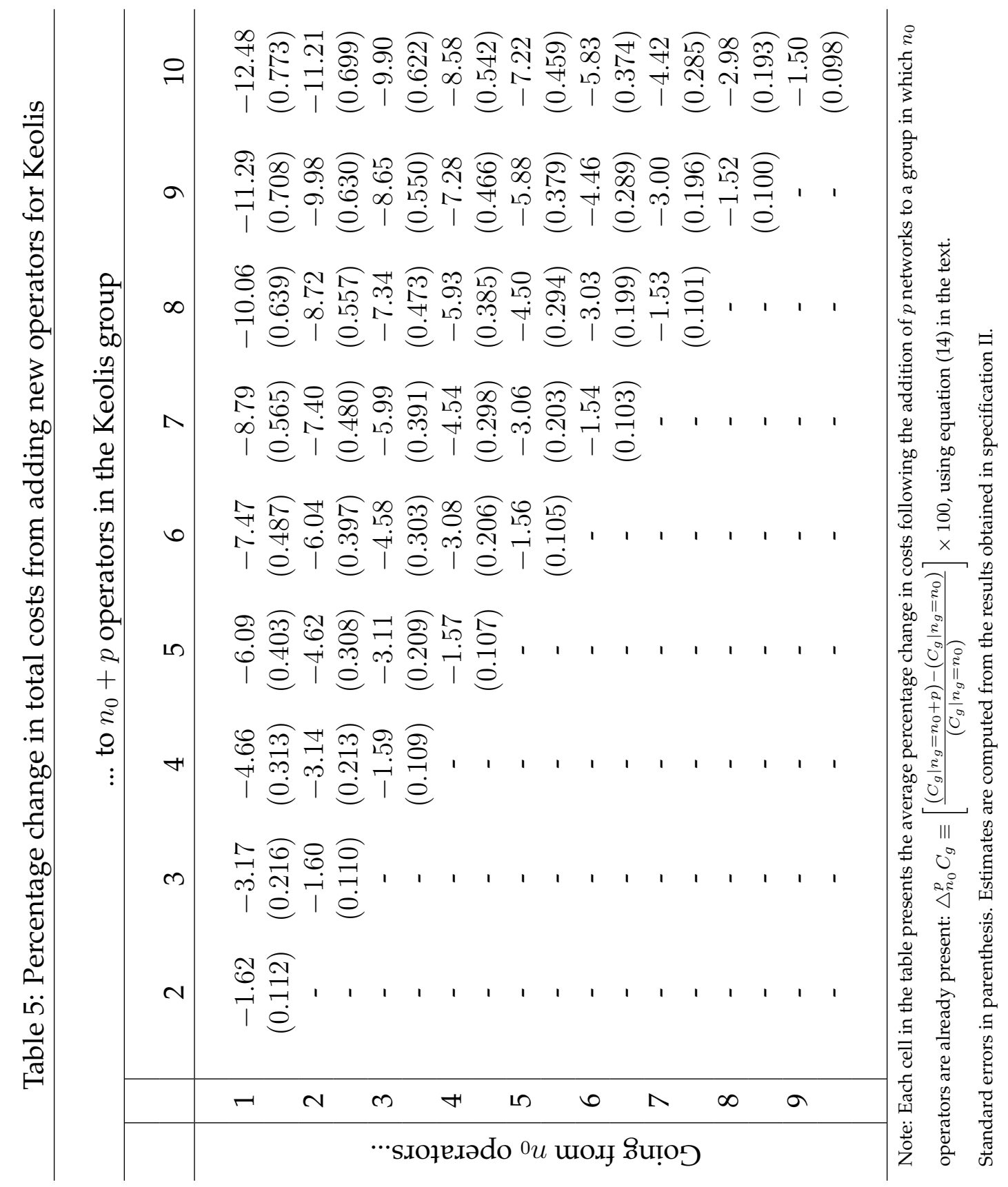




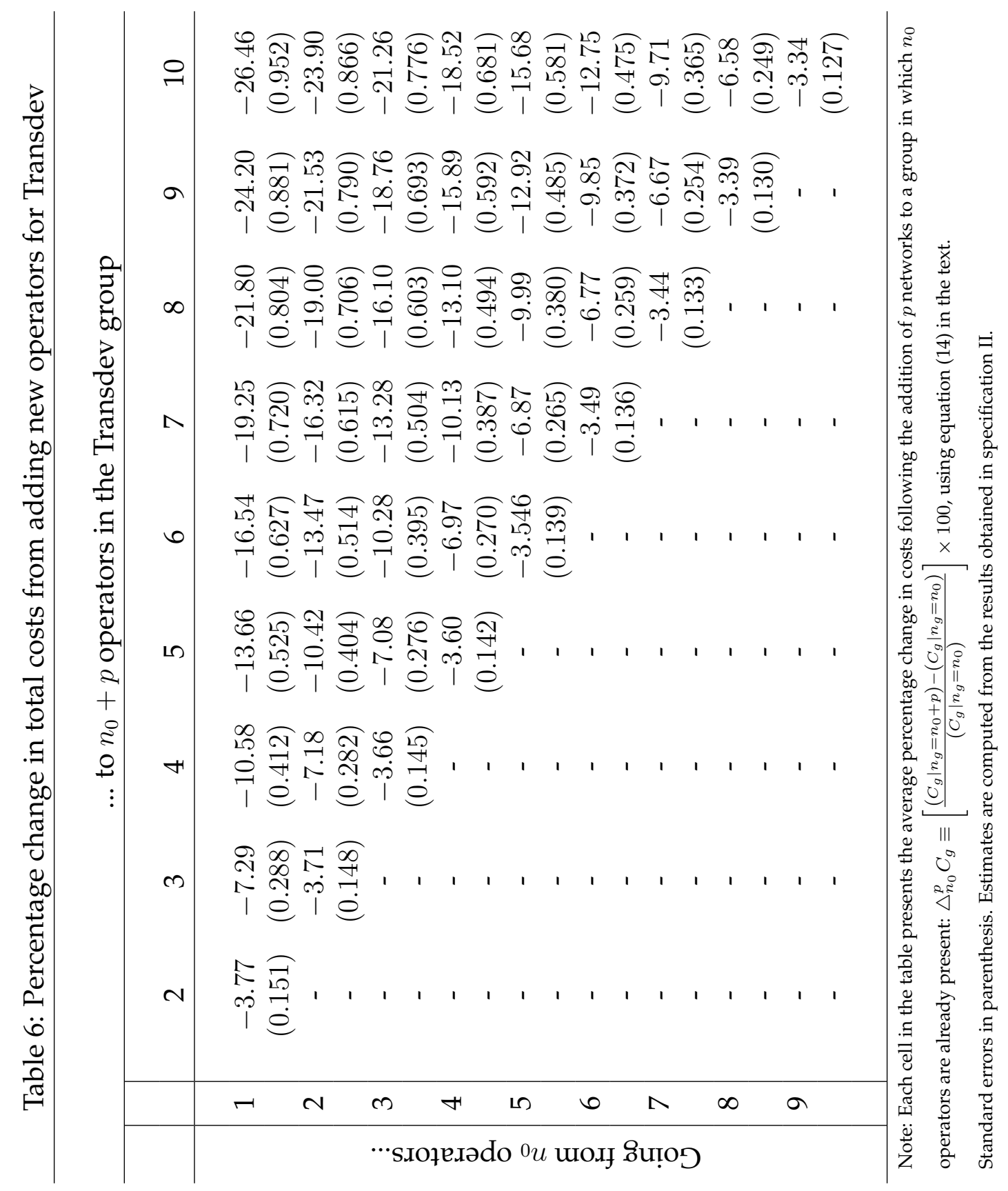

